of D.D.T., the toxicity of the latter is ascribed to the hydrochloric acid simultaneously produced either by elimination or reduction.

The insecticidal activity of a compound to which this hypothesis is applicable would then depend on the ease with which hydrochloric acid is produced, provided that the compound is stable enough to survive translocation to its site of action. Preliminary work has shown that some other compounds, for example, certain chlorinated cyclic polymethylenes and non-aromatic substituted ethanes susceptible to this decomposition are insecticidal, whereas related compounds from which hydrochloric acid elimination is not possible are inactive.

On the other hand, diphenyl trichlorethane ( $\mathrm{I}, \mathrm{X}=\mathrm{H}$ ) loses hydrochloric acid readily to alkali yet is relatively non-insecticidal. An additional factor, lipoid solubility of the molecule as a whole, is therefore operative. The chlorphenyl groups of D.D.T. would be expected to confer high lipoid solubility and thus high permeativity. The more polar dihydroxy derivative ( $\mathrm{I}, X=\mathrm{OH})$ and its diacetate, with lower lipoid solubilities, are less insecticidal than the dimethyoxy-analogue of D.D.T. (I, $X=$ $\mathrm{OMe}$ ).

Fuller details of this work will be published elsewhere.

H. Martin,

R. L. WAin.

University of Bristol Agricultural and

Horticultural Research Station, Long Ashton, Bristol.

\section{Experimental Corroboration of the Mechanism of Biological Action of Quinones of the Type of Vitamin K}

A нYРотнеsis was suggested ${ }^{1,3}$ in the course of chemical and biochemical studies of the antihæmorrhagic compounds that the activity of the quinones of the vitamin $K$ group is due to their biooxidative decomposition to phthalic acid and is largely a function of their capacity for transformation into this acid. It is phthalic acid that is apparently to be regarded as the carrier of the biological properties of such quinones.

These statements were based on the following experimental evidence. (1) The quinones of the type of vitamin $\mathrm{K}$ are extremely liable to transformation into phthalic acid merely when warmed with water ${ }^{2}$. (2) The structural peculiarities of quinones that give them anti-hæmorrhagic activity are also responsible for their capacity for transformation into phthalic acid $^{3}$. (3) The transformation of such quinones into phthalic acid is linked with the capacity of their molecules for tautomeric transition to a peculiar alycyclical system which is easily oxidizable into phthalic acid1,2,3. (4) It was found, on the other hand, that phthalic acid itself possesses a weak ${ }^{4}$, and some of its derivatives, for example, diethylphthalate ${ }^{3}$, a significant, anti-hæmorrhagic activity. The smaller activity of phthalic acid as compared with diethylphthalate as well as with quinones of the vitamin $K$ type is presumably due to the rapid excretion of this acid from the organism (for details cf. ref. 3). (5) The quinones of the vitamin $K$ type undergo very rapid changes in the blood (cf. J. V. Scudi and R. P. Buchs ${ }^{5}$ ), although their anti-hæmorrhagic action is known to appear only after a considerable lapse of time. This likewise suggests that these quinones apparently do not circulate within the organism as such at the moment when the anti-hæmorrhagic action becomes manifest, and that the effect at issue is elicited not by these substances but by the products of their transformation.

It occurred to us that one of the most conclusive pieces of evidence supporting the above suggestions as to the mechanism of biological action of the quinones of the vitamin $K$ type would be their trans. formation within the organism into phthalic acid. It seemed, therefore, worth while to study the metabolism of both phthalic acid and of 2-methyl-1,4naphthoquinone (the so-called vitamin $\mathbf{K}_{\mathbf{3}}$ ) in the dog and man.

Upon repeated subcutaneous administration to dogs (weighing 12-13 kgm.) of appreciable doses of a. rather concentrated aqueous solution of a bisulphite derivative of 2-methyl-1,4-naphthoquinone (total dose about $0.8 \mathrm{gm}$.) phthalic acid was isolated from the urine and afterwards identified as phthalic anhydride. Urine was shown to lack both 2-methyl1,4-naphthoquinone and its bisulphite derivative as well as 2-methyl-3-oxy-1,4-naphthoquinone (phthiocol). Phthalic acid was also found in human urine upon subcutaneous injection of $50 \mathrm{mgm}$. bisulphite derivative of 2-methyl-1,4-naphthoquinone dissolved in water. Nevertheless, phthalic acid itself as well as its di-sodium salt are practically completely excreted after subcutaneous injection of an aqueous solution both in man and the dog without undergoing any changes. This was shown by $\mathrm{J}^{\text {. Pohl }}{ }^{6}$ in the dog and by us in man. The urine of a control man or dog does not contain phthalic acid at all. Hence it follows that phthalic acid is the metabolic end product of 2-methyl-1,4-naphthoquinone.

Thus, our previous hypothesis as of the mechanism of biological action of quinones of the vitamin $\mathrm{K}$ group is substantiated not only by the antihæmorrhagic activity of phthalic acid but also by the capacity of such quinones for transformation into phthalic acid both in vitro and in vivo.

Mention must also be made of the publication by K. P. Link et $a l_{.}{ }^{3}$ on the mechanism of the hæmorrhagic action of $3,3^{\prime}$-methylene-4, $4^{\prime}$-dioxydicumarin, which is an antagonist of vitamin $K$. It was shown by these authors that salicylic acid possesses the same type of biological action as $3,3^{\prime}$-methylene4,4'-dioxydicumarin. As the former is apparently the metabolic product of the latter, it may be regarded as the carrier of its hæmorrhagic functions.

These data become particularly interesting if we recall that, according to our finding, phthalic acid is not only the metabolic end-product of quinones of the vitamin $K$ type, but obviously also the carrier of their anti-hæmorrhagic function.

M. M. ShEMIAKIn.

L. A. Schukina.

All-Union Institute of Experimental Medicine, Moscow.

${ }^{1}$ Shemiakin, M. M., Schukina, L. A., and Shvezov, J. B., Nature, 151 , 585 (1943).

Schukina, I. A., Shvezov, J. B., and Shemiakin, M. M., J. Obschei Khimii, 13, 327 (1943).

shemiakin, M. M., Schukina, L. A., and Shvezov, J. B., J. Obschei Khimii, 13, 398 (1943).

- Pakendorf, K. G., Kudriashev, B. A., and Lasareva, E. N., Doklady Akad. Nauk U.S.S.R., 31, 484 (1941).

scudi, J. V., and Buchs, R. P., J. Biol. Chem., 144, 599 (1942).

- Pohl, J., Biochem. Z., 16, 68 (1909).

' Link, K. P., Overman, R. S., Sullivan, W. R., Huebner, Ch. F., and Scheel, L. D., J. Biol. Chem., 147, 468 (1943). 